\title{
人参サポゲニンのシリカゲル液・固クロマトグラフィー における溶出挙動
}

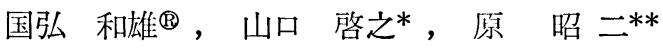 \\ (1981 年 9 月 21 日受理)
}

薬用人参サポゲニンと，その誘導体の高性能液体クロマトグラフィーで，シリカゲル，二成分溶媒樂 の保持比と溶出溶媒成分のモル濃度の相関を調査し, 各サポゲニンの溶出挙動と溶媒の溶出強度を定量 的に評価した。二成分系溶媒の希釈剂として, へキサン，ベンゼン，ジクロロメタンを, 強溶出溶媒に は, ジェチルェーテル $\left(\mathrm{B}_{1}\right)$, 酶酸エチル $\left(\mathrm{B}_{2}\right)$, アセトン $\left(\mathrm{B}_{3}\right)$, テトラヒドロフラン $\left(\mathrm{B}_{4}\right)$, ジオキサ ソ $\left(\mathrm{B}_{5}\right), 2-$ プロパノール $(\mathrm{AB})$, を用いた. サポゲニンとその誘導体の溶出は，パナキサジオールが パナキサトリオールより早く, 又, ベンゾェートはアセテートより, アセテートは遊離サポゲニンより 早かった．強溶出溶媒の溶出力は， $\mathrm{B}_{1}<\mathrm{B}_{2}<\mathrm{B}_{4} \approx \mathrm{B}_{5}<\mathrm{B}_{3}<\mathrm{AB}$ であった.

\section{1 緒 $\overline{\overline{\bar{n}}}$}

医薬品としての天然物, 生薬の成分を分離・同定し, 定量することは, その品質を評価し, 生物活性等を研究 する上で重要な過程である．各種のクロマトグラフィー は有効な方法として応用されるが, 特に高性能液体ク口 ママドラフィー（HPLG）は，その高分離能や迅速性か ら大きな役割を果たしつつある. しかし，充てん剂，溶 離液などの分離システムの選択は, 経験や勘に基づく試 行錯誤の繰り返しであり，最適条件を見いだすことは困 難な作業である，そこで，分離条件の最適化を系統化す ることは, 研究の能率化・高度化に 有用な試みと言兄 る.

Snyder は, 液・固クロマトグラフィー (LSC) の溶 媒と溶質分子の吸着剂表面に打ける競合のモデルを基礎 として溶媒強度の概念を提出し, そのパラメーター $\left(\varepsilon^{\circ}\right)$ を実験的に算出した ${ }^{1)}$. 又, Neher は, シリカダル薄層 クロマトグラフィー（TLG） のデータから, 等溶出力 を持つ二成分溶媒組成を相対的に評価しようと試みた2). 著者らの一人, 原は, 溶媒 - 溶質間の吸脱着平衡に質量 作用の法則を適用して導かれた, 保持比と溶媒濃度の関 俰

$\log k^{\prime}=\mathrm{c}-\mathrm{n} \log X_{\mathrm{s}}$

* 湧永薬品 (株) 中央研究所: 広島県高田郡甲田町下甲 立 1624

** 東京薬科大学 : 東京都八王子市堀之内 1432
が，シリカゲルを充てん剤とする二成分溶媒系の LSG で多くの化合物について成り立つことを確認している3). ここで, $k^{\prime}$ は保持比, $X_{\mathrm{s}}$ は強溶出溶媒成分の $\mathrm{mol} /$ $\mathrm{mol} \%, \mathrm{c}, \mathrm{n}$ は定数である.

今回著者らは, 薬用人参のサポゲニンとその誘導体に ついてシリカゲル，三成分溶媒系での $k^{\prime}$ と $X_{\mathrm{s}}$ の相関 を調査し, サポゲニンの溶出挙動及び溶媒の溶出強度を 定量的に評価することを試みた。

\section{2 実験}

\section{1 装}

送液ポンプとして SP 024 型 (日本分光製), 注入器 として VL 611 型 (日本分光製), 検出器として示差屈 折計（LDG 製）を使用した.

\section{$2 \cdot 2$ カラム}

$250 \mathrm{~mm} \times 4 \mathrm{~mm}$ i. d. のステンレスカラム管に球状シ リカゲル [ワコーゲル LG-5K, 孔径 $90 \AA$, 粒径 5 $\mu \mathrm{m}$ (和光純薬) ], をクロロホルムのスラリーとしてカ ラム管に入れ，加圧送液して充てんした.

\section{3 試 薬}

薬用人参 (panax ginseng) より抽出精製したサポニン を分解して panaxadiol (PD), panaxatriol (PT) を得 た4)5). 更に各々をピリジン中で無水酢酸によりアセチ ル化, ピリジン中で塩化ベンゾイルによりベンゾイル化 $し て$, panaxadiol acetate(PDA), panaxatriol acetate 
(PTA), panaxadiol benzoate (PDB), panaxatriol benzoate $(\mathrm{PTB})$ ，を得た。それぞれ TLG の挙動とIR， NMR スペクトルを標品と比較して 構造を確認した. 又, 他のデータ ${ }^{8) 9)}$ との相関を可能とするため, 保持挙 動既知のコレステロール（和光純薬, 試薬特級）を基準 物質として用いた。

溶離溶媒は市販品 (和光純薬, 試薬特級) を使用した。

\subsection{HPLC 操作}

流速を $1.0 \mathrm{ml} / \mathrm{min}$ ，圧力を $(30 \sim 50) \mathrm{kg} / \mathrm{cm}^{2}$ に設 定した. サポゲニン試料を $(1 \sim 5) \mathrm{mg} / \mathrm{ml}$ の割合で溶 離溶媒（不溶の場合はジクロロメタン）に溶解して試料 液とし， (5〜10) $\mu \mathrm{l}$ の試料液をカラムに注入した. 温 度を $(23 \pm 2)^{\circ} \mathrm{C}$, 湿度を $(60 \pm 5) \%$ に設定した室内で HPLGを行った.

保持比 $k^{\prime}$ は次の式を用いて計算した. $k^{\prime}=\left(t_{\mathrm{R}}-t_{\mathrm{O}}\right) / t_{\mathrm{O}}$, ただし， $t_{\mathrm{R}}$ は保持時間, $t_{\mathrm{O}}$ はホールドアップタイムで, ヘキサンを注入して測定した。

\section{3 結果と考察}

\section{1 サポゲニンの構造と溶出挙動}

試料として用いた PD，PT 及びそれぞれのアセテー ト, ベンゾェート及びュレステロールの構造式を Fig. 1 に示す.

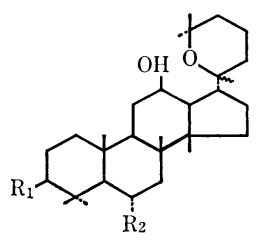

1. $\mathrm{R}_{1}=\mathrm{R}_{2}=\mathrm{OH} \quad$ (PT)

2. $\mathrm{R}_{1}=\mathrm{OH}: \mathrm{R}_{2}=\mathrm{H} \quad(\mathrm{PD})$

3. $\mathrm{R}_{1}=\mathrm{R}_{2}=\mathrm{OAc} \quad$ (PTA)

4. $\mathrm{R}_{1}=\mathrm{R}_{2}=\mathrm{OBz} \quad$ (PTB)

5. $R_{1}=O A c: R_{2}=H(P D A)$

6. $\mathrm{R}_{1}=\mathrm{OBz}: \mathrm{R}_{2}=\mathrm{H}(\mathrm{PDB})$

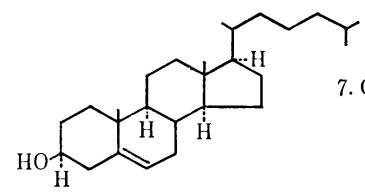

7. CHOLESTEROL

Fig. 1 Structual formulas of triterpenoid sapogenins and their derivatives

シリカゲル LSG における溶質の溶出挙動は, シリカ ゲル表面のシラノール基に対する溶質と溶媒分子の吸 · 脱着モデルから説明できる. この場合, 水素結合能が重 要な相互作用であるから, 溶質の構造と保持挙動との相 関を検討するため, 水素結合能の無いへキサンを希釈溶 媒として用い, 種々の強溶出溶媒を加えて二成分系を調
製した。

著者らの一人, 原は, 溶離溶媒を希釈剂 : ヘキサン $(\mathrm{O})$, ベンゼン $(\mathrm{P})$, ジクロロメタン $(\mathrm{N})$, 強溶出溶 媒: ジェチルエーテル $\left(\mathrm{B}_{1}\right)$, 酢酸エチル $\left(\mathrm{B}_{2}\right)$, アセ卜 ソ $\left(\mathrm{B}_{3}\right)$ ，テトラヒドロフラン $\left(\mathrm{B}_{4}\right)$, ジオキサン $\left(\mathrm{B}_{5}\right)$, 2-プロパノール (AB) に分類し ${ }^{3)}$, 溶媒の最適化を系 統化している. ここではへキサン/強溶出溶媒, すなわち $\mathrm{O}+\mathrm{B}_{1}, \mathrm{O}+\mathrm{B}_{2}, \mathrm{O}+\mathrm{B}_{3}, \mathrm{O}+\mathrm{B}_{4}, \mathrm{O}+\mathrm{B}_{5}, \mathrm{O}+\mathrm{AB}$ の二 成分系を適用し， $\mathrm{B}$ 又は $\mathrm{AB}$ の濃度を変学各試料の保持 容量を测定した。

既に Soczewinski らによって TLC で6), 又, 原ら によってステロイド7) 10), ペプチド11), アルカロイド12), その他の HPLG で $k^{\prime}$ と $X_{\mathrm{s}}$ の両対数との直線関係 (1) 式が実験的に証明されているが, 薬用人参のサポゲ ニンとその誘導体においても広い濃度範困で同じ関係が 成り立つことを確認した. PD，PDA，PT，PTBの実験 データからの相関直線を Fig. 2 に示した. 相関係数は 0.994〜0.999 であった.

ここに得られた結果から, 試料の各溶媒系での溶出順 位について考察した. 溶出順位は大部分の溶媒系におい $\tau$

$\mathrm{PD}>\mathrm{PT}$; ベンゾェート>アセテート>遊離サポゲニ บ

であった．ただし，不等号の大きさは溶出が早いこと を意味する.これは, 吸・脱着において, 溶質分子中の 水酸基が最も大きな影響を持つこと, その数が溶質分子 の充てん剤への吸着を強くすることを示している．同一 のサポゲニンについてペンゾェートはアセテートより吸 着が弱い. 又, 水素結合力の強い溶媒として, $\mathrm{B}_{4}, \mathrm{~B}_{5}$ を 含む $\mathrm{O}+\mathrm{B}_{4}, \mathrm{O}+\mathrm{B}_{5}$ では PTA と $\mathrm{PTB}$ の溶出挙動が 近接している. $\mathrm{O}+\mathrm{AB}$ と $\mathrm{O}+\mathrm{B}$ 系の溶媒とは溶出挙動 が異なり，アセテートとベンゾェートとの分離係数は, 後者より前者で大きくなる. 又, 溶出順位の逆転が観測 された（試料 4,5 ).

$\mathrm{O}+\mathrm{B}_{1}$ 及び $\mathrm{B}_{2}$ 系を適用した場合のように, 基準物質 として用いたコレステロールの溶出挙動は, サポゲニン 類と平行しないことがあり, 強溶出溶媒の組成が異なる とサポゲニン類との相対的な溶出順位も変化する.

\section{2 溶離溶媒の溶出力の評価}

3.2.1 強溶出溶媒強溶出溶媒の相対強度をより 定量的に 評価するため, 一定の試料 PTB について, $\mathrm{O}+\mathrm{B}$ 及び $\mathrm{O}+\mathrm{AB}$ のすべての溶媒の $k^{\prime}$ と $X_{\mathrm{s}}$ の関 係を同一の図にプロットし，実線で示した (Fig. 3). 又, 他の試料 PT, PDA, PTA, PDB, PTB, コレステ 

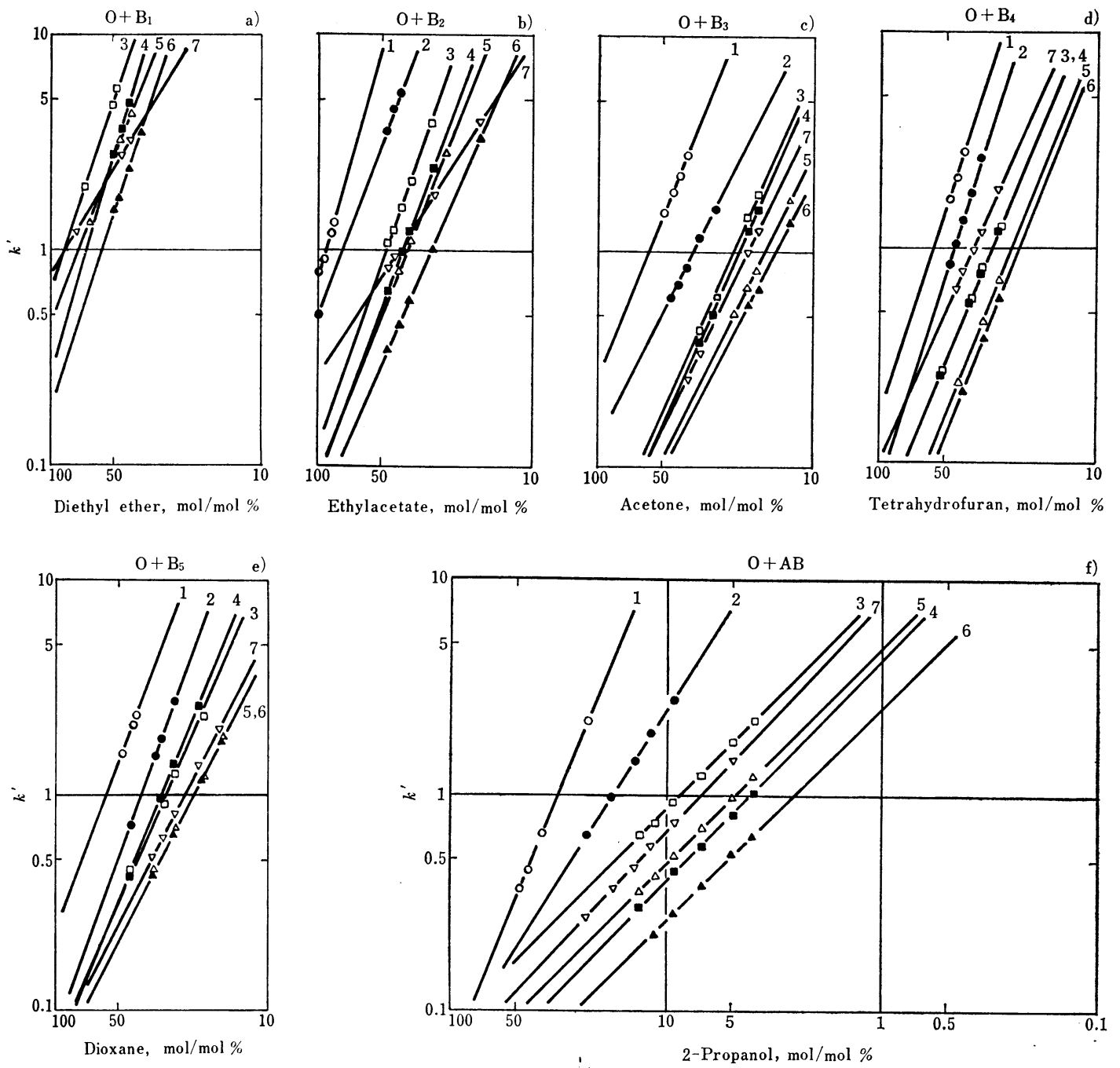

Fig. 2 (a) $\sim$ (f) Correlation between the logarithm of the capacity ratio $\left(k^{\prime}\right)$ and the logarithm of the stronger solvent composition in hexane-the stronger solvent binary system

Samples_- $:$ panaxatriol; 2 : panaxadiol; 3 : panaxatriol acetate; 4 : panaxatriol benzoate; $5:$ panaxadiol acetate; 6 : panaxadiol benzoate; $7:$ cholesterol; Solvent systems— $\mathrm{O}+\mathrm{B}_{1}=$ hexane-diethyl ether; $\mathrm{O}+\mathrm{B}_{2}=$ hexane-ethyl acetate; $\mathrm{O}+\mathrm{B}_{3}=$ hexane-acetone; $\mathrm{O}+\mathrm{B}_{4}=$ hexane-tetrahydrofuran; $\mathrm{O}+\mathrm{B}_{5}=$ hexane-dioxan; $\mathrm{O}+\mathrm{AB}=$ hexane-2-propanol

ロールについては, 定数 $\mathrm{c}, \mathrm{n}$ の $\mathrm{PD}$ との相対值を計算 した. 試料により相対強度は異なるが，この図から，強 容出溶媒の相対的な強度を推定することができる.

強溶出溶媒のサポゲニン類への溶出力に関する実験結 果 (Fig. 3) から, 同一の溶質についての溶出力の順位 は,ほぼ次のようになる。

$\mathrm{O}+\mathrm{B}_{1}<\mathrm{O}+\mathrm{B}_{2}<\mathrm{O}+\mathrm{B}_{4} \approx \mathrm{O}+\mathrm{B}_{5}<\mathrm{O}+\mathrm{B}_{3}<\mathrm{O}+\mathrm{AB}$ そこで, 強溶出溶媒の溶出力は

$$
\mathrm{B}_{1}<\mathrm{B}_{2}<\mathrm{B}_{4} \approx \mathrm{B}_{5}<\mathrm{B}_{3}<\mathrm{AB} \text { となる. }
$$

3.2 .2 希釈溶媒 3.1 及び 3.2.1 ではへキサン $(\mathrm{O})$ を希橎溶媒として用いたが，弱い水素結合能を持つペン ゼン ( P) やジクロロメタン (N) も希釈溶媒として使 用できる.そこでこれらの希䆏剤相互の溶出強度を比較 するため, 強溶出溶媒として酢酸エチル $\left(\mathrm{B}_{2}\right)$ を用い, $\mathrm{O}+\mathrm{B}_{2}, \mathrm{P}+\mathrm{B}_{2}, \mathrm{~N}+\mathrm{B}_{2}$ における $X_{\mathrm{s}}$ と $k^{\prime}$ との相関を $\mathrm{PD}$ と $\mathrm{PT}$ を溶質として調査した. その結果, $k^{\prime}$ と $X_{\mathrm{s}}$ の間の相関直線は, 軸上の一点に収れんすることが分か った (Fig. 4). 又希釈剤相互の溶出能は 


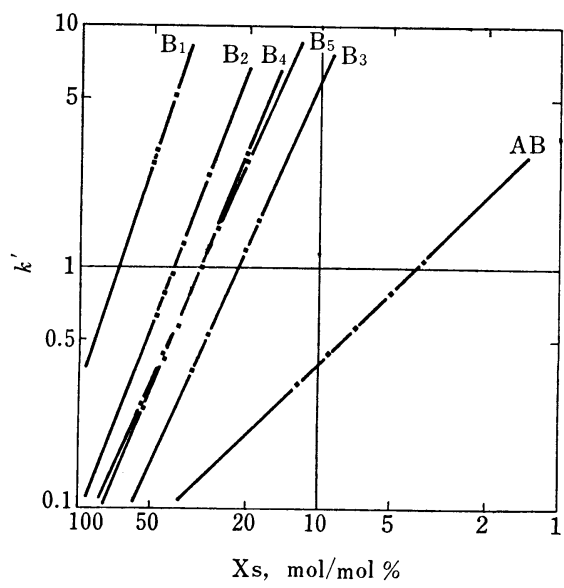

Fig. 3 Logarithm of capacity ratios on silica gel as a function of the logarithm of the concentration of the stronger solvent-hexane

Sample: panaxatriol benzoate; Solvent components as in Fig. 2.
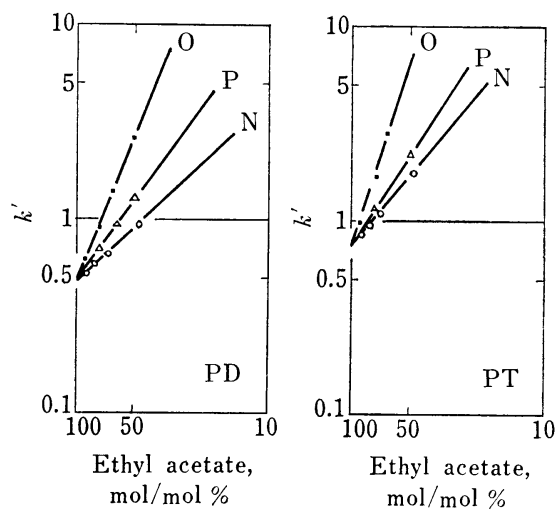

Fig. 4 Correlation between the logarithm of the capacity ratio $\left(k^{\prime}\right)$ and the logarithm of the stronger solvent composition in diluentethyl acetate binary system

Samples: $\mathrm{PD}=$ panaxadiol; $\mathrm{PT}-$ panaxatriol; Diluents: $\mathrm{O}=$ hexane; $\mathrm{P}=$ benzene; $\mathrm{N}=$ dichloromethane

$$
\mathrm{O}<\mathrm{P}<\mathrm{N}
$$

である。

\section{3 溶媒最適化の考察}

Fig. 3 に示した $k^{\prime}$ と $X_{\mathrm{s}}$ の相関から, 一定の $k^{\prime}$ の点から横軸の平行線を引き，これと各相関值線の交点 を求める. この交点のX軸上の読みが強溶出溶媒のモル 濃度を示し, 等しい保持比を持つそれぞれの溶媒の濃度
を求めることができる. 更に $3 \cdot 2 \cdot 1$ で指摘したように, 溶出順位の逆転する事実などにも注目し，与えられた試 料に対して好ましい分離係数を持つ溶媒の種類と濃度を 最適化することができる.

ここに述べたサポゲニンの溶出挙動及び溶媒の相対強 度に関する知見は，類線化合物をはじめとして，広い範 囲の混合物試料の分離の設計にも適用できる.

(1980 年 10 月，本会符 29 年会において発表)

\section{交献}

1) L. R. Snyder : "Principles of Adsorption Chromatography”, p. 192, (1968), (Marcel Dekker, New York).

2) R. Neher : Steroid Chromatography, 2nd. Ed. p. 249, (1964), (Elsevier, Amsterdam).

3) 原 昭二, 森 定雄, 花井俊彦 : “クロマトグラ フィー分離システム”，p. 161 (1981)，(丸善).

4) 藤田路一，系川秀治，柴田承二：薬誌，82，1634 (1962).

5) S. Shibata, O. Tanaka, K. Sōma, Y. Iida, T. Ando, H. Nakamura : Tetrahedron Lett., 207 (1965).

6) E. Soczewinski, J. Jusiak : Chromatographia, 14, 23 (1981).

7) S. Hara : J. Chromatogr., 137, 41 (1977).

8) S. Hara, Y. Fujii, M. Hirasawa, S. Miyamoto: J. Chromatogr., 149, 143 (1978) .

9) S. Hara, M. Hirasawa, S. Miyamoto, A. Ohsawa : J. Chromatogr., 169, 117 (1979).

10) S. Hara, A. Ohsawa : J. Chromatogr., 200, 85 (1980).

11) S. Hara, A. Ohsawa, A. Dobashi : J. Liq. Chromatogr., 4, 409 (1981).

12) S. Hara, N. Yamauchi, C. Nakae, S. Sakai : Anal. Chem., 52, 33 (1980).

$$
\text { 幽 }
$$

Retention behavior of panax ginseng sapogenins in silica gel liquid-solid chromatography Kazuo Kunihiro, Hiroyuki Yamaguchi*, and Shoji HARA** (*Central Research Laboratory, Wakunaga Pharmaceutical Co., Ltd., 1624, Shimokotachi, Koda-cho, Hiroshima; **Tokyo College of Pharmacy, 1432, Horinouchi, Hachioji-shi, Tokyo)

To optimize the conditions of liquid-solid chromatographic system, it is necessary to examine systematically the retention behavior of given samples. In this paper, correlation between logarithm of capacity ratio $\left(k^{\prime}\right)$ and logarithm of molar concentration of strong eluent $\left(X_{\mathrm{s}}\right)$ on silica gel-binary solvent system was quantitatively investigated. Sapogenins and its derivatives from panax ginseng were used as model samples. Experiments of HPLG were performed using a S.P. 024 pump (JASGO), VL 611 injector (JASCO), RI detector (LDC), and stainless steel column (250 $\mathrm{mm} \times 4 \mathrm{~mm}$ i.d.) packed with spherical shaped silica gel [LG-5K(Wako pure chem.)] as adsorbent. Binary solvent consisted of diluent [hexane (O), benzene 
$(\mathrm{P})$, dichloromethane $(\mathrm{N})$ ] and strongly eluting solvent [diethyl ether $\left(B_{1}\right)$, ethyl acetate $\left(B_{2}\right)$, acetone $\left(B_{3}\right)$, tetrahydrofuran $\left(\mathrm{B}_{4}\right)$, dioxan $\left(\mathrm{B}_{5}\right)$, 2-propanol $\left.(\mathrm{AB})\right]$. All experimental results were obtained at ambient temp $\left\{(23 \pm 2)^{\circ} \mathrm{C}\right\}$ and humidity $\{(60 \pm 5) \%\}$. Panaxadiol was eluted faster than panaxatriol. Benzoate was eluted faster than acetate, and the latter faster than free sapogenin. The order of strength of the eluents were found to be $B_{1}<B_{2}<B_{4} \approx B_{5}<B_{3}<$ $\mathrm{AB}$, and the diluents $\mathrm{O}<\mathrm{P}<\mathrm{N}$.

(Received Sept. 21, 1981)

\section{Keyword phrases}

liquid-solid chromatography; silica gel-binary solvent system; panax ginseng sapogenins.

\title{
ガスクロマトグラフィーを用いたヒト血しょう総脂質の 高級脂肪酸の定量法について
}

\author{
小沢 昭夫，高柳香都子，藤田 孝夫*，平井 愛山蚛， \\ 浜崎智仁, 寺野隆, 田村泰, 熊谷 朗** \\ (1981 什 9 月 21 日受理)
}

\begin{abstract}
エスキモー人の疫学調查により魚脂中に多く含まれる $\omega-3$ の高級多価不飽和脂肪酸の抗血栓, 抗動脈 硬化作用が注目されている。 ヒト血しょう総脂質中の高級脂肪酸を精度よく測定するためにキャピラリ 一カラムを装着したガスクロマトグラフを用い血しょうより Folchらの方法で抽出し $\mathrm{BF}_{3}$ メノールで エステル化した試料を分離分析したところ良好な成績が得られた. 本法での抽出操作を含めた再現性は アラキドン酸，エイコサペンタエン酸，ドコサヘキサエン酸のいずれについても5\%以下と良好で各 冬のメチルエステルを用いて得られた添加回収率もほぼ $100 \%$ と良好な值を示した. 又検量線もいず れの脂肪酸について良好な成績が得られ，又実際の実験食投与の健常人において子有意の脂肪酸の変動 が恋められたことから本法は血しょら総脂質中の高級脂肪酸の定量法の一つとして有用と考えられる.
\end{abstract}

\section{1 緒}

グリーンランドのエスキモー人についての疫学調査の 結果, 魚脂中に多く含まれる $\omega-3$ の多価不飽和脂肪酸 特に $\omega-3$, エイコサペンタェン酸（以下 $\mathrm{C}_{20: 5}$ と略記） に抗血栓, 抗動脈硬化作用のあることが明らかにされ, 血栓性疾患の一手段として注目を集めている1). それに 伴い血しょら中の高級脂肪酸の測定は必すのものとな りつつあるが，従来から用いられている（10２0)\%の DEGS を用いた充てんカラム2)3) では $\omega-6, \mathrm{C}_{20: 4}$ と $\mathrm{C}_{22: 1}$ との分離ができないなどの欠点があった. そこで 著者らは DEGS キャピラリーカラムを用いて EPAを 中心に血しょう中の総脂質中の高級脂肪酸を定量的に測

*日本水産（株）中央研究所：東京都八王子市北野町 1134-1

** 千葉大学医学部筑二内科：千葉県千葉市亥鼻 1-8-1
定する方法を確立したので以下に報告する.

\section{2 試薬, 器具及び装置}

\section{1 試薬及び器具}

アラキドン酸 $\left(\omega-6, \mathrm{C}_{20: 4}\right.$ 以下 $\mathrm{C}_{20: 4}$ と略記 $), \mathrm{C}_{20: 5}$, ドコサヘキェン酸 $\left(\omega-3 \mathrm{C}_{22: 6}\right.$ 以下 $\mathrm{C}_{22: 6}$ と略記) 及び その他の脂肪酸メチルェステルの標準品はアプライドサ イェンスラボラトリー社の製品を用いた。 クロロホル ム，メタノール，エタノール，へキサン，ベンゼン，水 酸化カリウム, 塩酸, 無水硫酸ナトリウム，14\%トリ フルオロベンゼン $\left(\mathrm{BF}_{3}\right)$ は和光純薬の特級品を用いた. 又血しょう試料の調製にはテルモ社製のへパリンナトリ ウム入りベノジェクト真空採血管を用いた。

\section{2 装}

ガスクロマトグラフは日立製 063 型水素炎イオン化検 出器付きのものを用いた. データ処理装置としては島津 製クロマトパック G-R1A を用いた. 